\title{
Research on the Impact of Hospital Information System Use on Doctors' Job Performance
}

\author{
Cuiyue Zhu \\ Graduate school \\ Tianjin University of Traditional Chinese Medicine \\ Tianjin, China \\ fsy123610@163.com
}

\author{
Jian Zhang* \\ School of management \\ Tianjin University of Traditional Chinese Medicine \\ Tianjin, China \\ zjian619@126.com \\ *Corresponding author
}

\begin{abstract}
The implementation of the hospital information system contributes to the hospital informationization construction and is an important part of China's medical system reform. Informatization construction has been carried out in hospitals across the country, but high investment does not necessarily lead to outstanding performance results, and there is a paradox of IT productivity. This paper analyzes the influence mechanism of the hospital information system on doctors' work performance from two aspects: personal perception of system and individual self-efficacy. Empirical studies have found that doctors' perception of usefulness, perception system customization and self-efficacy have a significant positive impact on doctors' job performance during the use of information systems. This article will deepen and enrich the understanding of hospital information system performance theory, which will help further research on information system performance in the future.
\end{abstract}

Keywords-Performance; Self-Efficacy; Use of hospital information systems; Influences

\section{INTRODUCTION}

\section{A. Backgrounds}

With the improvement of medical level and people's medical awareness, hospitals at all levels in China face more patients and more complicated workflows, to support the clinical work of front-line doctors, simplify work processes, improve the quality of diagnosis and treatment, and provide patients with better medical treatment. Experience, $a$ hospital information system came into being.

As a system that is not yet fully mature, the application of hospital information systems depends on the convenience and perfection of information system functions and the effective use of the system by relevant hospital departments and medical personnel. In the process of practice, China's medical information construction still encounters many problems. On the one hand, the high cost of information system purchase and maintenance does not significantly promote hospital performance growth. On the other hand, hospital executives are not sufficiently aware of the factors affecting the effective use of the system, and cannot adopt effective strategies to improve, so that the hospital information management control has little effect.[1] In the face of the black hole problem of IT investment, domestic and foreign scholars have introduced many theories to study, but there are still many controversies in the evaluation of information system performance.

From a theoretical point of view, this paper will enrich and supplement the understanding of the use of hospital information systems through research. From a practical point of view, this paper helps the hospital management department to have a more comprehensive and in-depth understanding and understanding of the information system use behavior of frontline medical staff, so as to develop a more targeted performance incentive system and improve the work of medical staff. Performance to maximize the benefits of IT investments.

\section{B. Research model}

This paper takes hospital doctors as the research object, selects four variables of perceived usefulness, perceived ease of use, self-efficacy and perception system customization, and introduces the use of system performance as an intermediate variable to analyze the impact of the information system used on doctors' job performance. As shown in Fig. 1. [2]

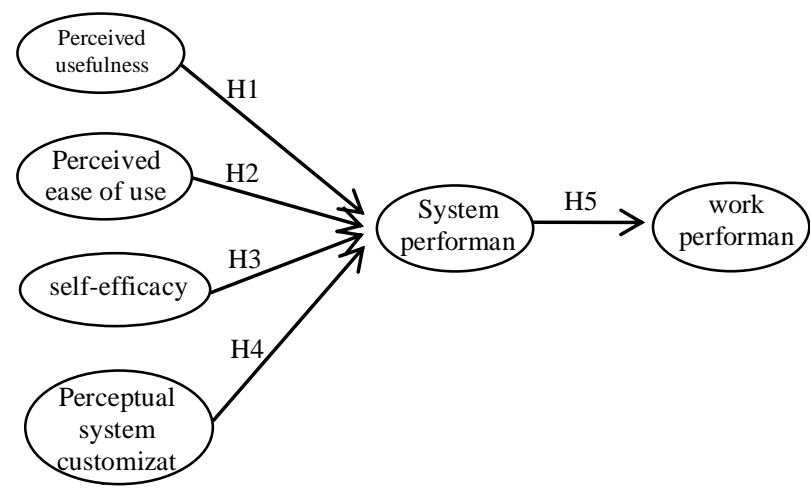

Fig.1. Research Model

According to Fishbein's theory of rational behavior, behavioral subjects achieve their influence on behavioral attitudes through beliefs and evaluations of their own behavioral outcomes. Behavioral attitude directly affects a person's willingness to act, and personal behavioral attitude is positively correlated with the behavioral will. Therefore, the 


\section{B. Measuring instrument}

This questionnaire uses the Likert five-level scale (1 means "very disagree" and 5 means "very agree"). The system perceived usefulness and perceived ease of use are based on the indicators used in the study by Venkatesh, Morris, which contain 4 items respectively; the information system selfefficacy is modified on the basis of Zhong Yuya, including 4 items; The perception system customization was modified based on the Bala \& Venkatesh research scale and consisted of 4 entries. [6-8]See Table 1 for details. correlation between self-efficacy and job performance and work behavior, and that this relationship is a causal relationship. In 2008, Cong Qing and Zhang Qiang found through empirical research that the stronger the self-efficacy of employees and the higher personal work performance and job satisfaction,[4] the paper puts forward the following assumptions:

H3: Self-efficacy has a positive impact on the use of system performance.

According to the TTF theory, the higher the level of interaction and matching between tasks and technologies, the better the individual's final performance. Performance can only be improved when the capabilities of information technology are better able to support the work of employees.[5] In 1995, Goodhue empirical research concluded that information characteristics, task characteristics, and individual characteristics affect the evaluation of task performance matching. At the same time, the interaction between task characteristics, individual characteristics and technical characteristics is related to the relationship between technology and user evaluation. Based on the above discussion, this paper proposes the following assumptions:

H4: Perceptual system customization has a positive impact on system performance

H5: Using system performance has a positive impact on job performance

\section{METHOD}

\section{A. Sample and setting}

In this study, doctors were used as research subjects to understand the impact of the use of hospital information systems on the performance of doctors' work, and to collect data in the form of questionnaires. In view of the fact that hospitals have been widely implemented in most hospitals in Tianjin, and the functions of each hospital information system are relatively small, we randomly selected doctors from some hospitals in Tianjin as research samples. Questionnaires are distributed and recycled using small-component workers. The team members are responsible for one or several hospitals. The doctors use the doctor's rest time to issue questionnaires, and the doctors fill them out on the spot and collect them on the spot. Finally, the data is collected. A total of 150 questionnaires were distributed and 133 questionnaires were collected, with a recovery rate of $88.67 \%$.
TABLE I. EVALUATION INDEX

\begin{tabular}{|c|c|}
\hline \multicolumn{2}{|c|}{ TABLE I. } \\
\hline Dimension & Measurement index \\
\hline Perceived usefulness & $\begin{array}{c}\text { Use the system to improve performance } \\
\text { Use the system to complete work tasks faster Use the system to } \\
\text { improve work efficiency } \\
\text { In general, the system is very useful for work. }\end{array}$ \\
\hline Perceived ease of use & $\begin{array}{c}\text { The user interface of the system is clear and easy to understand } \\
\text { Skilled in using the system is easy } \\
\text { Learning how to use the system is an easy task } \\
\text { In general, the system is easy to use }\end{array}$ \\
\hline Self-efficacy & $\begin{array}{c}\text { No one is pointing around, completing the system } \\
\text { Someone helped to complete the system when it was in trouble } \\
\text { Complete the system by referring to the system operation guide. } \\
\text { Have enough time to complete the system }\end{array}$ \\
\hline Perceptual system & $\begin{array}{c}\text { The package is allowed to be changed to better meet the needs } \\
\text { Adjust to improve its match to demand } \\
\text { customization }\end{array}$ \\
$\begin{array}{c}\text { Specific modifications to meet the requirements } \\
\text { Reconfig. to meet demand }\end{array}$ \\
\hline
\end{tabular}

\section{Ethical considerations}

The study collected data in the form of questionnaires, and all respondents had obtained informed consent. The survey is strictly anonymous and guarantees the privacy of hospitals and doctors

\section{RESULTS}

\section{A. Participants}

A total of 150 questionnaires were distributed and 133 questionnaires were collected, with a recovery rate of $88.67 \%$. Among the recovered questionnaires, the proportion of males was $58.6 \%$. The proportion of women is $41.4 \%$, the proportion of males and females is relatively even; the proportion of age distribution is $23.7 \%$, which is $61.7 \%$, which indicates that the questionnaire is mostly young doctors, which has good recognition and learning ability for information technology; $63.2 \%$ of doctors have been working in their hospital for 1-5 years. Correspondingly, the proportion of residents was $63.9 \%$. Most young doctors have short working hours and have a few years of exposure to hospital information systems. However, according to the results of the questionnaire, $81.2 \%$ of doctors often use the hospital information system every day, and the daily use frequency is very high, and it has strong information system usability. From the sample characteristics, the sample meets the requirements of this study. See Table II for details.

TABLE II. DEMOGRAPHIC INFORMATION

\begin{tabular}{|c|c|}
\hline Factors & Total-n (\%) \\
\hline Gender - \% & \\
\hline Female & $55(41.4)$ \\
\hline Male & $78(58.6)$ \\
\hline Age(in years) - \% & \\
\hline $23-29$ & $82(61.7)$ \\
\hline $\mathbf{3 0 - 3 9}$ & $32(24.1)$ \\
\hline $40-49$ & $14(10.5)$ \\
\hline
\end{tabular}




\begin{tabular}{|c|c|}
\hline \multicolumn{2}{|c|}{ Cont. to TABLE II } \\
\hline $50-59$ & $4(3)$ \\
\hline$\geq 60$ & $1(0.8)$ \\
\hline Operating hours(years) - \% & \\
\hline $1-5$ & $84(63.2)$ \\
\hline $6-10$ & $26(19.5)$ \\
\hline $11-15$ & $14(10.5)$ \\
\hline $16-20$ & $3(2.3)$ \\
\hline$>20$ & $6(4.5)$ \\
\hline Job title - \% & \\
\hline Resident & $85(63.9)$ \\
\hline Attending physician & $27(20.3)$ \\
\hline Deputy chief physician & $14(10.5)$ \\
\hline Chief physician & $7(5.3)$ \\
\hline System usage time(years) - \% & \\
\hline$<3$ & $83(62.4)$ \\
\hline $3-5$ & $33(24.8)$ \\
\hline $6-10$ & 12(9) \\
\hline$>10$ & $5(3.8)$ \\
\hline System usage frequency - \% & \\
\hline Almost not & $3(2.3)$ \\
\hline Occasionally & $11(8.3)$ \\
\hline General & $11(8.3)$ \\
\hline
\end{tabular}

\begin{tabular}{|c|c|}
\hline Often & $31(23.3)$ \\
\hline Use every day & $77(57.9)$ \\
\hline
\end{tabular}

\section{B. SEVQUAL theory}

According to the correlation analysis method, the correlation between variables is studied, and the Pearson correlation coefficient is used to indicate the strength of the correlation, as shown in Table III. All variables showed significants, and the correlation coefficient values were 0.282 , $0.301,0.290,0.366$, and 0.206 , both of which were greater than 0 , which means that there is a positive correlation between the five items. Linear regression analysis was performed as shown in Table IV and V Perceived usefulness, self-efficacy, and perception system customization have a significant positive impact on the use of system performance. The use of system performance will have a significant positive impact on overall job performance. H1, H3, H4, and H5 are all obtained. Support, but perceived ease of use does not affect the use of system performance, $\mathrm{H} 2$ is not supported, and that is perceived ease of use does not affect the use of system performance.

TABLE III. CORRELATION ANALYSIS

\begin{tabular}{|c|c|c|c|c|c|c|c|c|}
\hline & Average & $\begin{array}{l}\text { Standard } \\
\text { deviation }\end{array}$ & $\begin{array}{c}\text { Overall job } \\
\text { performance }\end{array}$ & $\begin{array}{c}\text { Use system } \\
\text { performance }\end{array}$ & $\begin{array}{l}\text { Perceived } \\
\text { ease of use }\end{array}$ & $\begin{array}{l}\text { Perceived } \\
\text { usefulness }\end{array}$ & $\begin{array}{c}\text { Self- } \\
\text { efficacy }\end{array}$ & $\begin{array}{c}\text { Perceptual system } \\
\text { customization }\end{array}$ \\
\hline Overall job performance & 7.32 & 1.58 & 1 & & & & & \\
\hline Use system performance & 3.96 & 0.76 & $0.282 * *$ & 1 & & & & \\
\hline Perceived ease of use & 3.96 & 0.7 & $0.301 * *$ & $0.656 * *$ & 1 & & & \\
\hline Perceived usefulness & 4.09 & 0.66 & $0.290 * *$ & $0.728 * *$ & $0.756^{* *}$ & 1 & & \\
\hline Self-efficacy & 4.01 & 0.63 & $0.366 * *$ & $0.529 * *$ & $0.595 * *$ & $0.531 * *$ & 1 & \\
\hline $\begin{array}{l}\text { Perceptual system } \\
\text { customization }\end{array}$ & 3.61 & 0.79 & $0.206^{* *}$ & $0.545^{* *}$ & $0.520^{* *}$ & $0.484^{* *}$ & $0.533 * *$ & 1 \\
\hline \multicolumn{7}{|c|}{$<0.05^{* *} \mathbf{p}$} & & \\
\hline
\end{tabular}

IV. DISCUSSION

\section{A. Paying attention to the usefulness and customization of system functions during development}

Perceived usefulness, self-efficacy, and perceived system customization have a significant positive impact on the use of system performance. This shows that in the use of hospital information systems, doctors' perception of usefulness and perception of the system and the sense of self-efficacy of doctors play an important role in promoting job performance.

This requires enterprises to pay attention to the usefulness and customization of system functions when developing information systems. Doctors also need to enhance their selfefficacy in their daily work to strengthen the professionalism of nursing homes.

\section{B. Hospitals should pay attention to the construction and maintenance of information system}

Using system performance has a significant positive impact on overall job performance. This shows that the use of information systems can promote the performance of doctors. Hospitals should pay attention to the construction and maintenance of hospital information systems and support the daily use of doctors. Doctors also need to strengthen their familiarity and understanding of information systems and use information systems to improve their performance.
TABLE IV. REGRESSION ANALYSIS

\begin{tabular}{|c|c|c|c|c|c|c|}
\hline & \multirow{2}{*}{ Model } & \multicolumn{2}{|c|}{$\begin{array}{c}\text { Non-standardized } \\
\text { coefficient }\end{array}$} & \multirow{2}{*}{$\begin{array}{c}\begin{array}{c}\text { Standardization } \\
\text { coefficient }\end{array} \\
\text { Beta } \\
\end{array}$} & \multirow{2}{*}{$\mathrm{T}$} & \multirow{2}{*}{ Sig } \\
\hline & & B & $\begin{array}{c}\text { Standard } \\
\text { error }\end{array}$ & & & \\
\hline \multirow{5}{*}{1} & (Constant) & -.240 & .307 & & -.782 & .436 \\
\hline & $\begin{array}{l}\text { Perceived } \\
\text { usefulness }\end{array}$ & .547 & .100 & .470 & 5.479 & .000 \\
\hline & $\begin{array}{l}\text { Perceived } \\
\text { ease of use }\end{array}$ & .110 & .100 & .100 & 1.103 & .272 \\
\hline & Self-efficacy & .242 & .089 & .198 & 2.720 & .007 \\
\hline & $\begin{array}{c}\text { Perceptual } \\
\text { system } \\
\text { customization }\end{array}$ & .154 & .066 & .160 & 2.324 & .022 \\
\hline \multirow{9}{*}{2} & (Constant) & .154 & .361 & & .428 & .670 \\
\hline & $\begin{array}{l}\text { Perceived } \\
\text { usefulness }\end{array}$ & .534 & .100 & .459 & 5.341 & .000 \\
\hline & $\begin{array}{c}\text { Perceived } \\
\text { ease of use }\end{array}$ & .110 & .101 & .101 & 1.093 & .276 \\
\hline & Self-efficacy & .212 & .090 & .174 & 2.348 & .020 \\
\hline & $\begin{array}{c}\text { Perceptual } \\
\text { system } \\
\text { customization }\end{array}$ & .175 & .068 & .181 & 2.568 & .011 \\
\hline & Gender & -.152 & .088 & -.099 & $\begin{array}{c}- \\
1.727\end{array}$ & .087 \\
\hline & Age & .042 & .103 & .047 & .406 & .686 \\
\hline & $\begin{array}{c}\text { Working } \\
\text { years }\end{array}$ & .086 & .092 & .119 & .930 & .354 \\
\hline & Job title & -.187 & .128 & -.216 & $\begin{array}{c}- \\
1.461\end{array}$ & .146 \\
\hline
\end{tabular}


TABLE V. REGRESSION ANALYSIS

Through the above research conclusions, in order to promote the effective use of hospital information systems by doctors, to give full play to the functions of information systems, and to improve the performance of doctors, this paper proposes the following recommendations:

From a hospital perspective, this paper demonstrates that the in-depth use of information systems can have a positive impact on a doctor's job performance. The management of the hospital should pay attention to the construction of the information system. In order to support the daily maintenance and operation of the system, recruit excellent computer talents to the information section to provide rear-end protection for the medical staff to use the information system. The hospital information department puts in a new system in the hospital and should provide training and guidance for medical staff so that medical staff can fully understand the various operations of the information system.

From the perspective of enterprises, when developing hospital information systems, enterprises must combine the needs of clinical medical staff, and take into account the differential diagnosis and treatment of different departments, and try to make the operation and functions simple and easy to use. To do this, enterprises need to recruit not only computersavvy programmers, but also AN in-depth understanding of the hospital, or external first-line medical staff to participate in the development of the system.

From the doctor's point of view, in the early stage of system use, doctors need to fully mobilize their subjective initiative, enhance self-efficacy, make full use of time to understand and learn the various functional operations of the new system, familiarize themselves with system operation as early as possible, and be proficient in applying information systems to themselves. Have enough confidence.

\begin{tabular}{|c|c|c|c|c|c|c|}
\hline & \multirow[t]{2}{*}{ Model } & \multicolumn{2}{|c|}{$\begin{array}{c}\text { Non-standardized } \\
\text { coefficient }\end{array}$} & \multirow{2}{*}{$\begin{array}{c}\begin{array}{c}\text { Standardization } \\
\text { coefficient }\end{array} \\
\text { Beta }\end{array}$} & \multirow[t]{2}{*}{$\mathrm{T}$} & \multirow[t]{2}{*}{ Sig. } \\
\hline & & B & Standard error & & & \\
\hline \multirow[b]{2}{*}{1} & (Constant) & 5.008 & .701 & & 7.139 & .000 \\
\hline & $\begin{array}{c}\text { Use system } \\
\text { performance }\end{array}$ & .585 & .174. & .282 & 3.361 & .001 \\
\hline \multirow{6}{*}{2} & (Constant) & 4.765 & .907 & & 5.252 & .000 \\
\hline & $\begin{array}{c}\text { Use system } \\
\text { performance }\end{array}$ & .572 & . 174 & .276 & 3.281 & .001 \\
\hline & Gender & -.200 & .271 & -.063 & -.739 & .461 \\
\hline & Age & .197 & .320 & .106 & .615 & .539 \\
\hline & Working years & .441 & .287 & .295 & 1.536 & .127 \\
\hline & Job title & -.294 & .399 & -.164 & -.738 & .462 \\
\hline
\end{tabular}

\section{REFERENCES}

[1] Zhong Yuya. Research on the influencing factors of mobile medical APP user acceptance behavior based on UTAUT theory [D]. Hangzhou: Hangzhou Normal University, 2017.(In Chinese)

[2] Delone W H, Mclean E. The Delone \& Mclean Model of Information Systems Success:A Ten-Year Update [J].Journal of Management Information Systems, 2003 (4):14-22.

[3] Tang Yamin. Workplace exclusion and employee turnover intention: the role of job insecurity and general self-efficacy [D]. Henan University, 2017.(In Chinese)

[4] Cong Qing, Zhang Qiang, Xiang Ming, Chen Yang. An Empirical Study on the Influence of College Students' General Self-efficacy on Job Satisfaction and Job Performance[J]. Journal of Chengdu University (Educational Science Edition), 2008(02): 1-2+8.(In Chinese)

[5] Han Jing, Cheng Huagang. The performance of clinicians in Sanjia Hospital of Tangshan City and its influencing factors Prime [J]. Medicine and Society, 2018, 31 (5): 69-71.

[6] Ding Jiapeng, Climbing, Wei Qin. HIS operation based on the concept of information technology infrastructure library Maintenance Management [J]. Chinese Hospital Management, 2017, 37 (10): 7172.(In Chinese)

[7] Research on Hospital Information System Construction in Medical Informatization[J]. Meng Xun. China Health Industry. 2016(35).(In Chinese)

[8] Hillol Bala and Viswanath Venkatesh. Changes in Employees' Job Characteristics During an Enterprise System Implementation: A Latent Growth Modeling Perspective[J]. MIS: Quarterly, 2013, 37(4):11131140 . 